Supporting Information

\title{
Capture of Iodine from Nuclear-Fuel-Reprocessing Off-Gas: Influence of Aging on Reduced Silver Mordenite Adsorbent after Exposure to $\mathrm{NO} / \mathrm{NO}_{2}$
}

Alexander I. Wiechert, ${ }^{1}$ Austin P. Ladshaw, ${ }^{1}$ Jisue Moon, ${ }^{2}$ Carter W. Abney, ${ }^{2}$ Yue Nan, ${ }^{3}$ Seungrag Choi, ${ }^{3}$ Jiuxu Liu, ${ }^{3}$ Lawrence L. Tavlarides, ${ }^{3}$ Costas Tsouris,,${ }^{1,2}$ Sotira Yiacoumi1 ${ }^{1,}$ ${ }^{1}$ School of Civil and Environmental Engineering, Georgia Institute of Technology; Austin P. Ladshaw is currently at Oak Ridge National Laboratory in the Energy and Transportation Science Division, ORCID 0000-0002-0157-6410

${ }^{2}$ Oak Ridge National Laboratory: Jisue Moon is in the Chemical Sciences Division; Carter W. Abney is currently at ExxonMobil Research \& Engineering Company, ORCID 0000-0002-18099577; Costas Tsouris is in the Energy and Transportation Science Division, ORCID 0000-0002$0522-1027$

${ }^{3}$ Department of Biomedical and Chemical Engineering, Syracuse University; Yue Nan is currently at BASF Catalysts (Shanghai) Co., Ltd., ORCID 0000-0001-8731-3568; Jiuxu Liu is currently at China National BlueStar (Group) Co., Ltd., ORCID 0000-0001-5488-5308;

* Corresponding Author: sotira.yiacoumi@ce.gatech.edu 

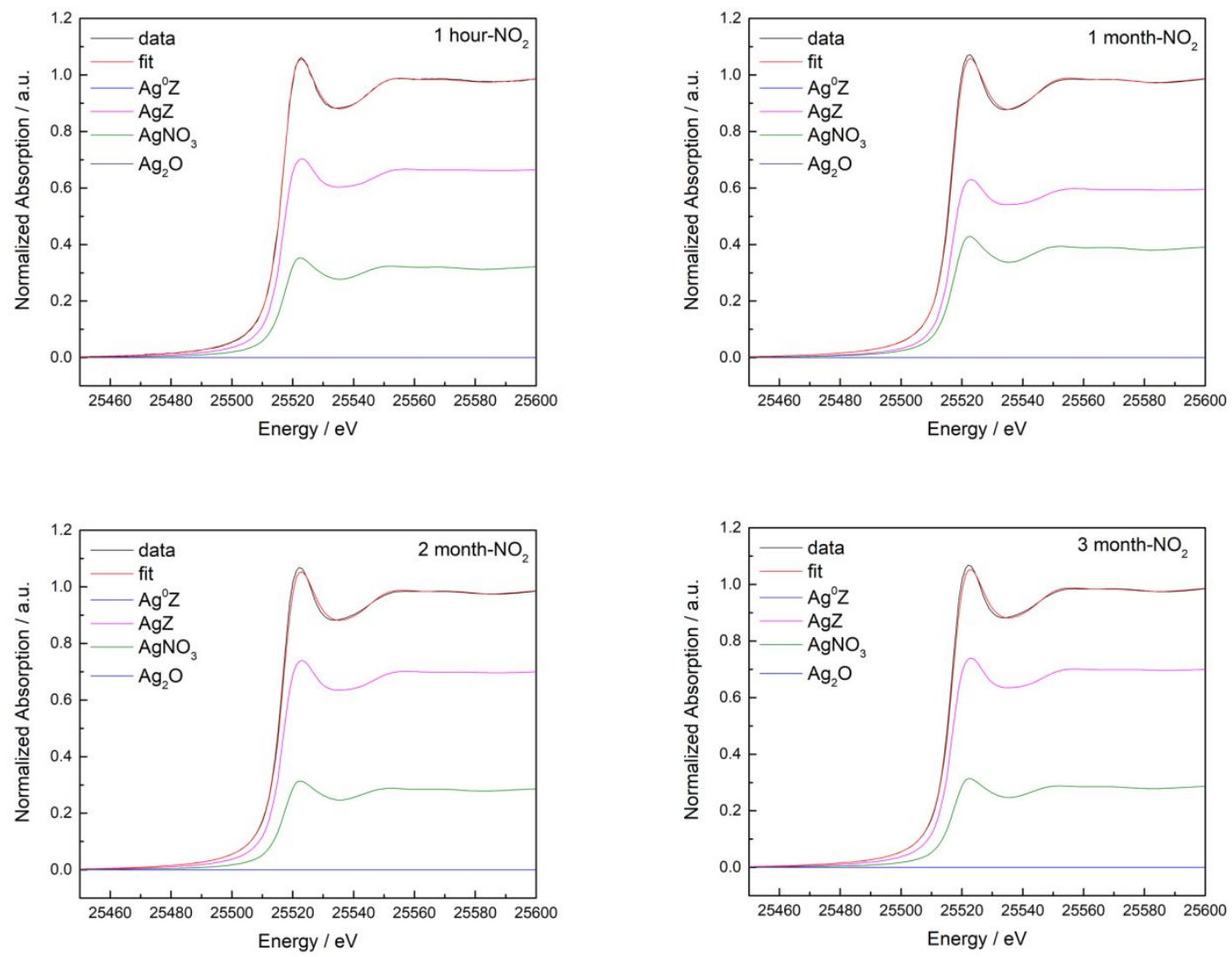

Figure S1. Linear combination fitting (LCF) for $\mathrm{Ag}^{0} \mathrm{Z}$ aged in $2 \% \mathrm{NO}_{2}$ in dry air using reference compounds $\mathrm{Ag}^{0} \mathrm{Z}, \mathrm{Ag}_{2} \mathrm{O}, \mathrm{AgNO}_{3}$, and $\mathrm{AgZ}$. Experimental data are in black and the LCF is in red. Reference standards used to achieve the LCFs are plotted beneath and scaled according to their contribution to the fit. 

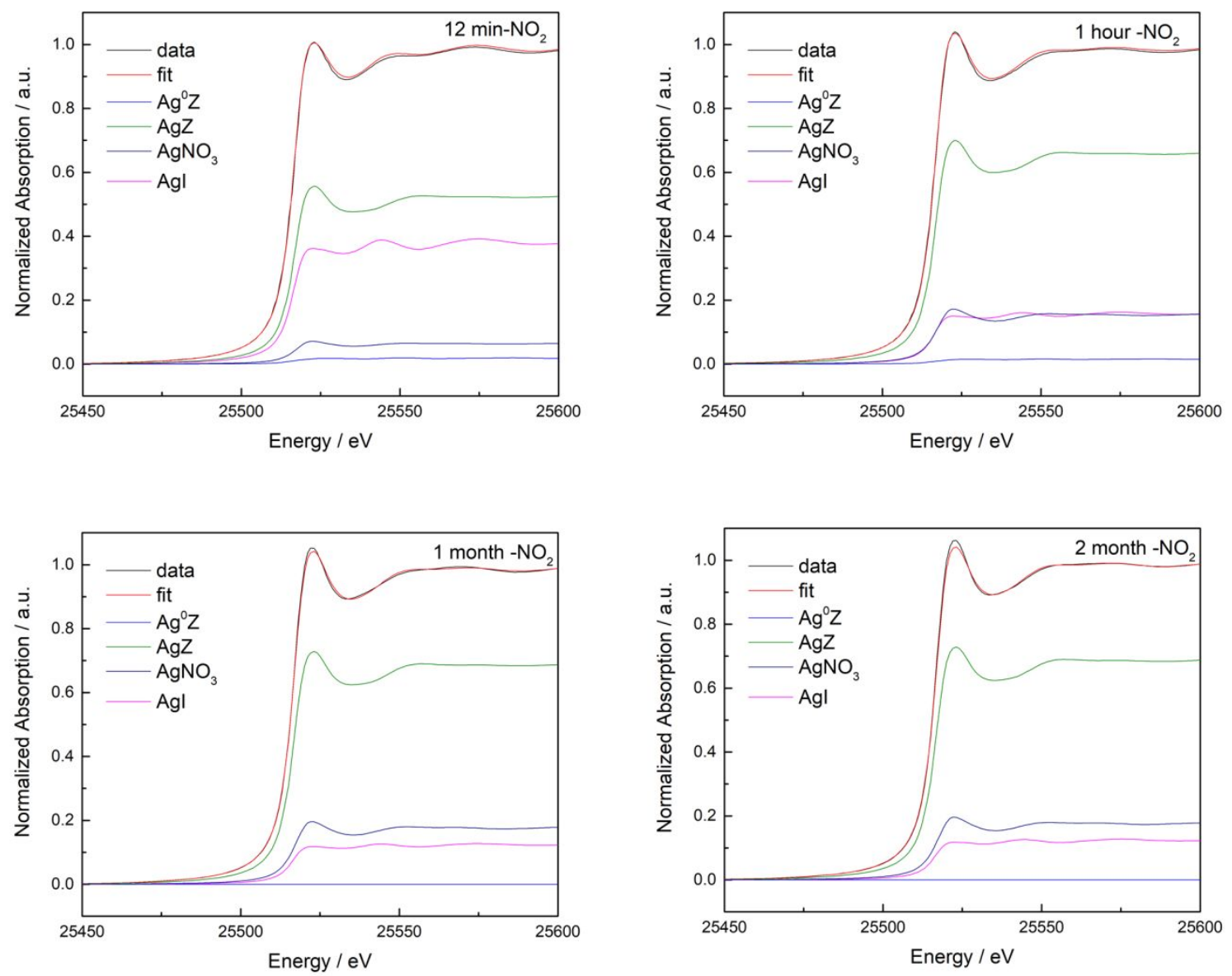

Figure S2. Linear combination fitting (LCF) for $\mathrm{Ag}^{0} \mathrm{Z}$ aged in $2 \% \mathrm{NO}_{2}$ in dry air and then exposed to iodine $\left(\mathrm{I}_{2}\right)$ at a concentration of $50 \mathrm{ppmv}$ in dry air using reference compounds $\mathrm{Ag}^{0} \mathrm{Z}$, $\mathrm{Ag}_{2} \mathrm{O}, \mathrm{AgNO}_{3}, \mathrm{AgZ}$, and $\mathrm{AgI}$. Experimental data are in black and the LCF is in red. Reference standards used to achieve the LCFs are plotted beneath and scaled according to their contribution to the fit. 

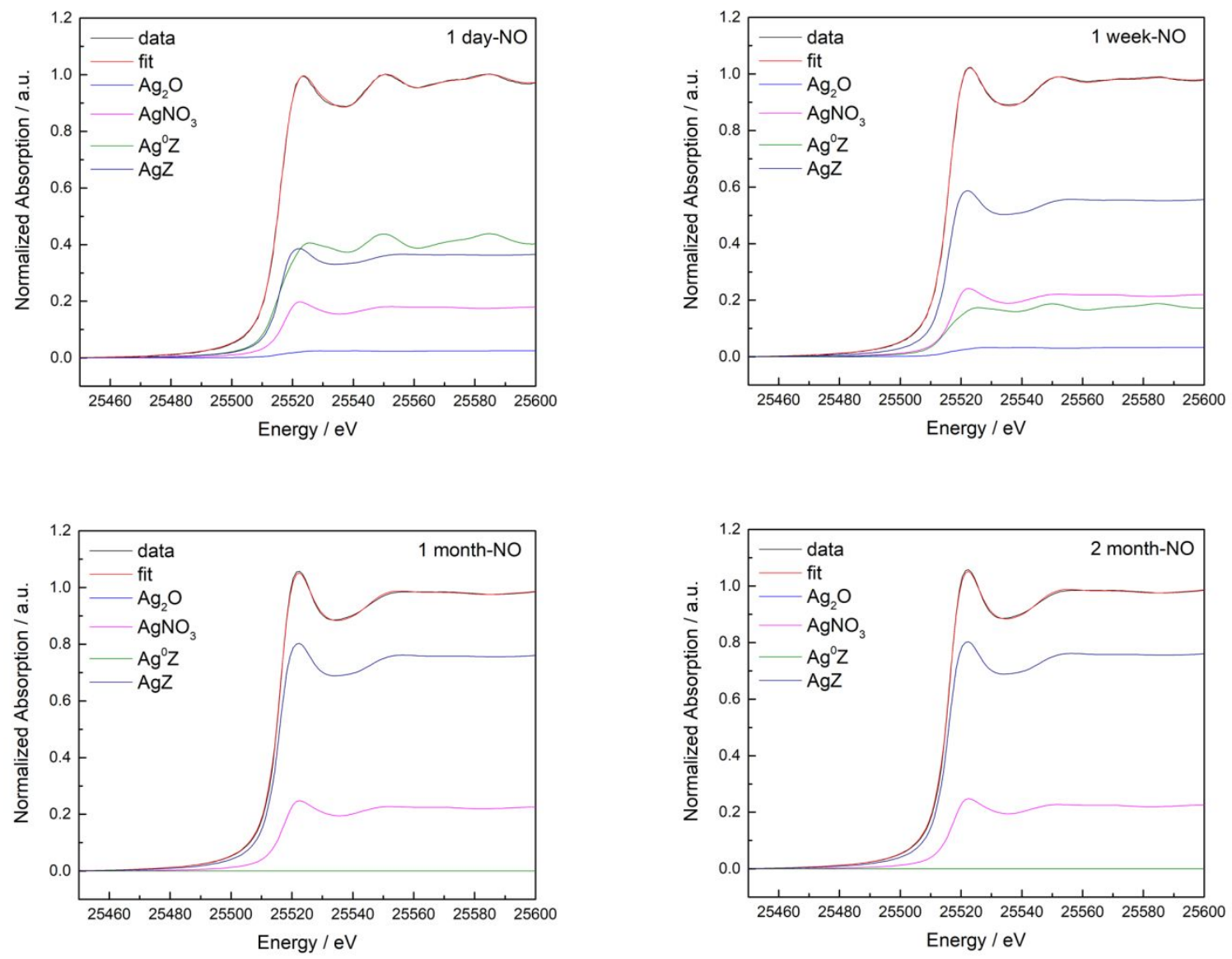

Figure S3. Linear combination fitting (LCF) for $\mathrm{Ag}^{0} \mathrm{Z}$ aged in $1 \% \mathrm{NO}$ in $\mathrm{N}_{2}$ using reference compounds $\mathrm{Ag}^{0} \mathrm{Z}, \mathrm{Ag}_{2} \mathrm{O}, \mathrm{AgNO}_{3}$, and $\mathrm{AgZ}$. Experimental data are in black and the $\mathrm{LCF}$ is in red. Reference standards used to achieve the LCFs are plotted beneath and scaled according to their contribution to the fit. 

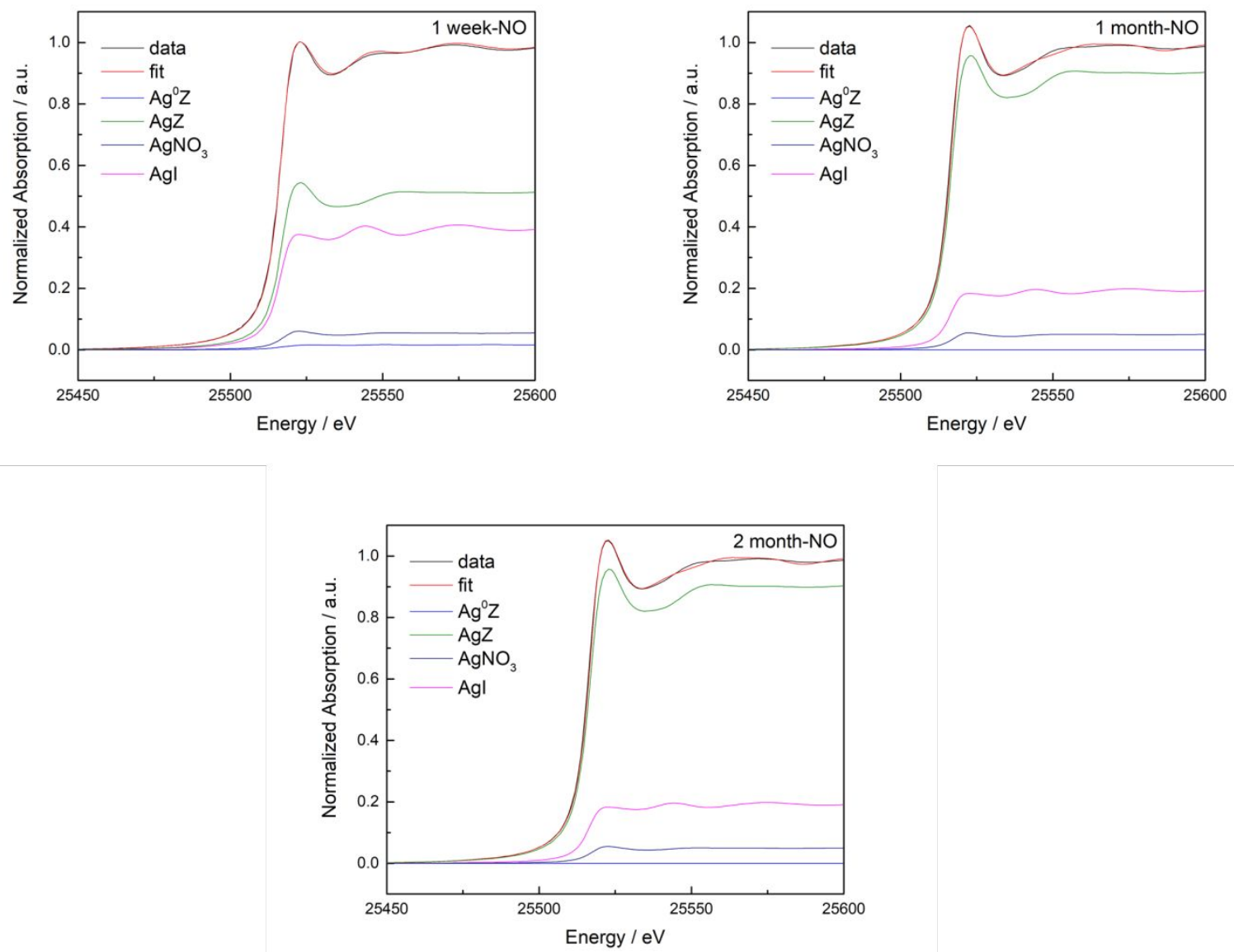

Figure S4. Linear combination fitting (LCF) for $\mathrm{Ag}^{0} \mathrm{Z}$ aged in $1 \% \mathrm{NO}$ in $\mathrm{N}_{2}$ and then exposed to iodine $\left(\mathrm{I}_{2}\right)$ at a concentration of $50 \mathrm{ppmv}$ in dry air using reference compounds $\mathrm{Ag}^{0} \mathrm{Z}, \mathrm{Ag}_{2} \mathrm{O}$, $\mathrm{AgNO}_{3}, \mathrm{AgZ}$, and AgI. Experimental data are in black and the LCF is in red. Reference standards used to achieve the LCFs are plotted beneath and scaled according to their contribution to the fit. 


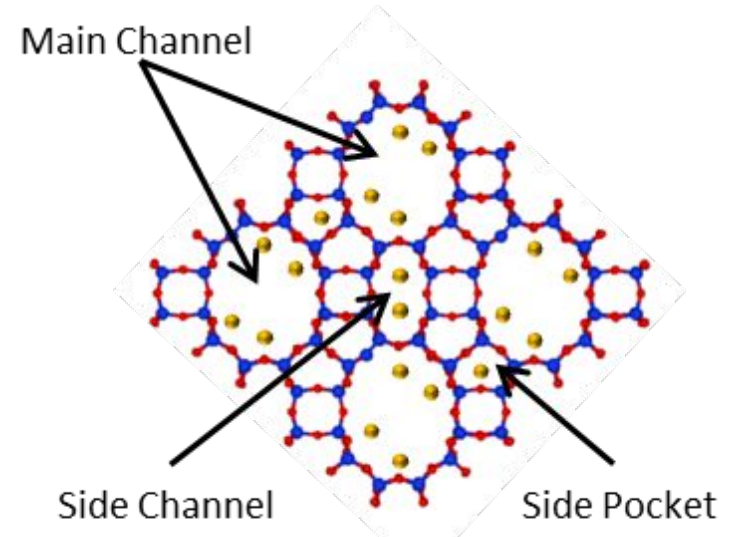

Figure S5. Structure of mordenite crystal where 12-member 7.0 x $6.5 \AA$ main channels, parallel 8member 5.7 x $2.6 \AA$ side channels, and 5-member side pockets with approximate binding sites shown. 